\title{
Novel Treatment Targets for Cerebral Edema
}

\author{
Brian P. Walcott • Kristopher T. Kahle • J. Marc Simard
}

Published online: 29 November 2011

(C) The American Society for Experimental NeuroTherapeutics, Inc. 2011

\begin{abstract}
Cerebral edema is a common finding in a variety of neurological conditions, including ischemic stroke, traumatic brain injury, ruptured cerebral aneurysm, and neoplasia. With the possible exception of neoplasia, most pathological processes leading to edema seem to share similar molecular mechanisms of edema formation. Challenges to brain-cell volume homeostasis can have dramatic consequences, given the fixed volume of the rigid skull and the effect of swelling on secondary neuronal injury. With even small changes in cellular and extracellular volume, cerebral edema can compromise regional or global cerebral blood flow and metabolism or result in compression of vital brain structures. Osmotherapy has been the mainstay of pharmacologic therapy and is typically administered as part of an escalating medical treatment algorithm that can include corticosteroids, diuretics, and pharmacological cerebral metabolic suppression. Novel treatment targets for cerebral edema include the $\mathrm{Na}(+)-\mathrm{K}(+)-2 \mathrm{Cl}(-)$ co-transporter (NKCC1) and the SUR1-regulated $\mathrm{NC}_{\mathrm{Ca}-\mathrm{ATP}}$ (SUR1/TRPM4) channel. These two ion channels have been demonstrated to be critical mediators of edema formation in brain-injured states. Their specific inhibitors, bumetanide and glibenclamide, respectively, are well-characterized Food and Drug Administration-approved drugs with excellent safety
\end{abstract}

\footnotetext{
B. P. Walcott $\cdot$ K. T. Kahle

Department of Neurosurgery, Massachusetts General Hospital, Harvard Medical School,

Boston, MA 02114, USA

J. M. Simard $(\bowtie)$

Department of Neurosurgery,

University of Maryland School of Medicine,

Baltimore, MD 21201, USA

e-mail: MSimard@smail.umaryland.edu
}

profiles. Directed inhibition of these ion transporters has the potential to reduce the development of cerebral edema and is currently being investigated in human clinical trials. Another class of treatment agents for cerebral edema is vasopressin receptor antagonists. Euvolemic hyponatremia is present in a myriad of neurological conditions resulting in cerebral edema. A specific antagonist of the vasopressin V1A- and V2-receptor, conivaptan, promotes water excretion while sparing electrolytes through a process known as aquaresis.

Keywords Cerebral edema $\cdot$ Hyponatraemia . Osmotherapy · NKCC1 · SUR1/TRPM4 · Vaptan · Glyburide

\section{Overview of Perturbations in Brain Fluid Homeostasis}

Cerebral edema in the neurointensive care setting can occur with a heterogenous group of neurological diseases, which typically fall under the categories of metabolic [1, 2], infectious [3], neoplastic [4], cerebrovascular [5-7], and traumatic $[8,9]$ brain injury. Irrespective of the inciting process, cerebral edema results in the pathological accumulation of fluid in the brain's intracellular and extracellular spaces. This occurs secondary to alterations in the complex interplay between 4 distinct fluid compartments within the cranium; fluid is present within: 1) the blood in the cerebral blood vessels, 2) the cerebrospinal fluid in the ventricular system and subarachnoid space, 3) the interstitial fluid of the brain parenchyma, and 4) the intracellular fluid of the neurons and glia. These fluid compartments are not isolated, and specific movements of solutes and water from one compartment to another occur under normal conditions. When dysregulation of this normally tightly controlled fluid balance occurs, in either the cerebral 
endothelial cells or the glia and neurons, volume and solute compositions are pathologically altered. From a fluid mechanics perspective, cerebral edema can result in increased intracranial pressure and death secondary to cerebral compression, due to the confined space within the fixed-volume cranium. Additionally, alterations in the precisely regulated ion gradients that typically exist across neuronal plasma membranes interfere with action potential generation, propagation, and metabolism, leading to dysfunction or death at the cellular level (Table 1).

\section{Cerebral Edema}

Historical conventions that dichotomize edematous states into "cytotoxic" or "vasogenic" categories are fading, as a better understanding of the pathophysiological processes that underlie edema formation in brain-injured states is elucidated. Although it is not optimal to use historical terms to describe new paradigms, conventional terms remain useful for differentiating the sequential events in edema development. After brain injury, alterations in ionic gradients lead to a step-wise temporal progression from what is known as cytotoxic (cellular) edema to ionic edema, and finally to vasogenic edema [10]. Ischemia leads to the cessation of primary active transport via $\mathrm{Na}^{+}-\mathrm{K}^{+}$-adenosinetriphosphatase (ATPase). Resultant to this, co-transporters (secondary active transport) and passive transporters (via ion channels) attempt to maintain cellular processes. By doing so, neurons and neuroglia accumulate osmotically active solutes intracellularly that cause cellular swelling and eventually passage of fluid into the extracellular space [11]. Although aquaporin-4 (AQP4), the most abundant water channel in the brain [12], has been implicated in the pathogenesis of post-stroke cerebral edema [13-16], the primary driver behind the formation of cytotoxic edema is truly the intracellular accumulation of sodium. Eventually, endothelial and neuroglial dysfunction impairs the ability to maindtain the integrity of the blood-brain barrier and vasogenic edema ensues.

Intracellular accumulation of sodium during the "cytotoxic (cellular) edema" phase derives from a multitude of transporters, including ion channels [10]. These ion transport proteins located in the cell membrane are activated or upregulated by factors associated with ischemia, such as elevated levels of extracellular potassium, alterations in $\mathrm{pH}$, inflammatory mediators (such as cytokines), and excitatory neurotransmitters (such as glutamate). An example of this is the NKCC1 transporter, which normally mediates sodium entry into cells [17-19]. Another example is an ion channel that has been shown to be transcriptionally upregulated after ischemic injury and trauma (i.e., the SUR1- regulated $\mathrm{NC}_{\mathrm{Ca}-\mathrm{ATP}}$ ) [SUR1/ TRPM4] channel). Activation of this channel results in the net influx of cations, driving the osmotic influx of water, thereby causing cellular swelling. In this review, we highlight the mainstay of pharmacological treatment for cerebral edema (osmotherapy), and then we focus on emerging treatment targets (i.e., the molecular processes that are actually responsible for edema formation, including the ion transporters, NKCC1 and SUR1/TRPM4, and vasopressin receptors).

\section{Osmotherapy}

Cerebral edema (and its effect, elevated intracranial pressure) occurs in a heterogeneous group of conditions treated in the neurointensive care unit. A profound and morbid example can be seen in the development of "malignant edema" in patients after large vascular territory ischemic stroke [20]. A multi-organ system treatment algorithm is the standard of care, with hyperosmotic therapy, in the form of mannitol and hypertonic saline, being the mainstays of traditional pharmacologic treatment. These powerful medications, which draw fluid into the intravascular space via an osmotic gradient, are effective and their use is widespread.

Among the various osmotic agents available for administration to treat cerebral edema, mannitol (administered rapidly in a $1 \mathrm{gm} / \mathrm{kg}$ bolus) has been the most commonly selected medication in the neurointensive care setting [21]. However, mannitol may lead to systemic hypotension, decreased cerebral perfusion, acute renal failure, and

Table 1 Novel targets to treat cerebral edema

\begin{tabular}{|c|c|c|c|}
\hline & NKCC1 & SUR1/TRPM4 & Vasopressin-receptor \\
\hline Location & $\begin{array}{l}\text { Neurons, neuroglia, endothelium, } \\
\text { choroid plexus }\end{array}$ & Neurons, neuroglia, endothelium & $\begin{array}{l}\text { Basolateral membrane of the cells lining } \\
\text { the collecting ducts of the kidneys }\end{array}$ \\
\hline Activation & ATP & Depletion of ATP & Vasopressin \\
\hline Specific antagonist & Bumetanide & Glyburide (glibenclamide) & Conivaptan \\
\hline Function & $\begin{array}{l}\text { Loads sodium and chloride into cells } \\
\text { to maintain level of }\left[\mathrm{Cl}^{-}\right]_{\mathrm{i}}\end{array}$ & Conducts monovalent cations & $\begin{array}{l}\text { Absorption of free water in collecting } \\
\text { tubule of kidney }\end{array}$ \\
\hline
\end{tabular}


delayed accumulation within the extravascular compartment that leads to a paradoxical rebound elevation in intracranial pressure [22, 23].

Another agent, hypertonic saline, is gaining increasing clinical interest due to its reported efficacy in treating cerebral edema and elevated intracranial pressure [24, 25]. Bolus dosing of hypertonic saline was first studied and documented almost 1 century ago by Weed and McKibben [26]. Hypertonic saline avoids the diuretic effect of mannitol while still being effective at reducing brain water. After administration, cerebral perfusion may actually be increased [27]. Various concentrations are clinically used, with as much as $30 \mathrm{~mL}$ boluses of $23.4 \%$ saline in a single dose. Rapid increases in serum sodium in this setting do not appear to cause the neurological complications that may be encountered in the context of rapid correction of hyponatremia [28].

Hypertonic saline has attributes beyond those expected for a simple osmotherapeutic agent. It affects the vasoregulatory, immunomodulatory, and neurochemical environment of the brain and the blood-brain barrier in ways that may benefit different categories of brain injury [2931]. In addition, the systemic effect of decreasing serum levels of arginine vasopressin may result in attenuating the development of cerebral edema at a critical level, the ionic stage of edema formation. Because arginine vasopressin stimulates the activity of the NKCC1 transporter, inhibition of this pathway plays a direct role in cell volume regulation during periods of ischemia and injury [32].

Several studies have demonstrated the efficacy of $23.4 \%$ hypertonic saline in the treatment of cerebral edema. Animal models of intracranial hypertension have demonstrated its efficacy without secondary complications [3335]. In a study published by Qureshi et al. [36], the effects of equi-osmolar doses of mannitol, 3\% hypertonic saline, and $23.4 \%$ hypertonic saline were investigated in a canine model of intracerebral hemorrhage. Immediate intracranial pressure reduction was most prominent after $23.4 \%$ hypertonic saline administration.

Only a few retrospective studies have examined the use of $23.4 \%$ hypertonic saline for the treatment of increased intracranial pressure in humans [24, 25, 37]. They all demonstrated a favorable effect in lowering intracranial pressure. A prospective study examining the effect of $23.4 \%$ hypertonic saline on intracranial pressure, cerebral perfusion pressure, and post-treatment brain tissue oxygen tension was carried out by Rockswold et al. [38]. They studied 25 consecutive patients with severe traumatic brain injury who were treated with $23.4 \%$ hypertonic saline. The authors demonstrated a significant decrease in intracranial pressure and an increase in brain tissue oxygen tension. At the same time, there was a significant increase in cerebral perfusion pressure. There are no definitive prospective data to advocate the use of one osmotic agent more than the other. Clinical practice guidelines at the Massachusetts General Hospital and other institutions incorporate the use of both agents. Administration of one does not preclude use of the other, and both are frequently alternated as needed.

When mass effect from lesional edema is too great for management by osmotherapy alone, evaluation of the patient for decompressive craniectomy is warranted. The surgical treatment of cerebral edema after massive middle cerebral artery infarction remains controversial. Historically, there has been reluctance to perform this operation because of a high rate of mortality and profound morbidity in survivors. Until recently, only case series and nonrandomized case-control studies suggested any benefit of decompressive craniectomy [39-43]. Several recent randomized controlled trials have demonstrated improved survival after decompressive craniectomy in certain stroke populations [6, 44-46]. These findings may have been influenced by the "early" timing of craniectomy in their protocols, potentially averting secondary brain damage associated with cerebral edema [47], although the inclusion of patients who may not have truly needed decompression also may have favorably influenced outcome. In contrast, worse outcomes were reported for decompressive craniectomy in traumatic brain injury when compared to maximal medical therapy alone [48]. However, applicability of these findings is tempered based on choice of operative technique (bifrontal procedure), a long study accrual time, differences in study arms (significantly more patients with bilaterally unreactive pupils included in the surgical group), and minimal mean elevations in intracranial pressure leading up to randomization. There exist no prospective trials regarding the effectiveness of decompressive craniectomy for infratentorial lesions.

\section{Other Treatments}

Several other pharmacologic methods, regarded as "second tier" therapies, can be used to treat cerebral edema. Barbiturates, such as pentobarbital, have been used to treat cerebral edema when osmotherapy fails. Their mechanism of action relates to their ability to lower the cerebral metabolic demand, thereby reducing intracranial blood volume. There is also evidence that barbiturates may have neuroprotective qualities as free radical scavengers [49]. Their clinical usefulness is limited by hypotension, induced coma (precluding a neurological examination), and increased risk of infection. Although there have been no randomized studies of barbiturates in cerebral infarction, their use in stroke generally is not recommended. However, barbiturates are still used in the setting of diffuse traumatic brain injury when intracranial pressure is refractory to 
osmotherapy, cerebrospinal fluid drainage, and surgical decompression.

Corticosteroids also are used to treat cerebral edema in the intensive care setting. Although there appears to be a strong benefit associated with the use of corticosteroids in vasogenic edema related to brain tumors, a large metaanalysis found no benefit of corticosteroids in ischemic stroke or intracerebral hemorrhage [50].

\section{Novel Targets for Cerebral Edema}

All of the treatments discussed thus far act in a nonspecific or indirect manner, either to remove edema fluid after it has formed (osmotherapy), or to compensate for edema by providing more space for brain swelling (barbiturates, craniectomy). Ideally, swelling would be prevented in the first place by inhibiting the formation of edema, a strategy that requires a deep understanding of the molecular mechanisms responsible for edema formation. Progress is being made in identifying such novel targets.

\section{NKCC1}

The ionic stage of edema represents the earliest phase of endothelial dysfunction (and by association, blood-brain barrier disruption), ultimately leading to vasogenic edema [51]. This is a critical stage in edema progression that heralds the accumulation of excess brain water. Once transendothelial permeability alterations are established, rapid changes in clinical status can occur. Treatments aimed at the inhibition of this process have the potential to arrest edema development and are currently the focus of clinical trials.

The depletion of ions and water from the brain's extracellular space as a result of cellular edema (impaired $\mathrm{Na}^{+}-\mathrm{K}^{+}$-ATPase activity) generates gradients that drive solutes and water from the vascular compartment into the extracellular space [52]. The secondary active cotransporter NKCC1, expressed on the luminal surface of endothelial cells, plays an important role in this process by loading sodium and chloride into the endothelial cells. Sodium inside the endothelial cell is then expelled into the brain's extracellular space by the activity of the $\mathrm{Na}^{+}-\mathrm{K}^{+}$ATPase, with chloride and water following through chloride channels and unidentified water channels, respectively. Under physiological conditions, the activity of NKCC1 modulates the level of $\left[\mathrm{Cl}^{-}\right]_{\mathrm{i}}$ in neurons, glia, endothelial cells, and choroid plexus epithelial cells, thereby helping to maintain proper cellular volume against changes in extracellular osmolality and intracellular solute content [53]. Brain-injured states associated with ischemia have been demonstrated to cause upregulation of the transporter. In a rat model of cerebral ischemia, NKCC1 transcripts and protein are significantly upregulated in cortical neurons, as well as in whole brain lysates $[54,55]$. These changes may occur in ischemic conditions secondary to elevated extracellular potassium and glutamate levels, substances known to stimulate NKCC1 activity in neurons and neuroglia [18, 56, 57]. Cytokines may also be involved in ischemiainduced upregulation of NKCC1, with interleukin- 6 shown to activate NKCC1 in capillaries [58].

Ischemia-induced increases in NKCC1 activity occur during the early stages of ischemia, as well during the reperfusion stage, when energy ([adenosine triphosphate] ATP) production is still possible. $\mathrm{NKCC} 1$ is a secondary active co-transporter, and ATP is needed to drive the activity of $\mathrm{Na}^{+}-\mathrm{K}^{+}$-ATPase, which establishes the inwardly directed sodium gradients required for co-transporter activity.

Bumetanide, a small molecule with a well-established safety profile, is a relatively specific inhibitor of NKCC1 at low concentrations [59]. Although this drug is commonly used as a diuretic, its excellent delivery across the bloodbrain barrier confers great usefulness for conditions affecting the central nervous system. Pilot studies are underway examining the efficacy of bumetanide administered with phenobarbital for the treatment of neurological disorders, including neonatal seizures (ClinicalTrials.gov identifier No. NCT00830531), and in adults the medically intractable and surgically unresectable temporal lobe epilepsy associated with medial temporal lobe sclerosis or various cortical malformations [60]. Preliminary studies suggest that bumetanide may be used at doses that provide specific inhibition of CNS NKCC1, without producing significant diuresis. The ionic regulation of cell volume via this channel may have implications in the treatment of edema in a wide range of neurological diseases, such as traumatic brain injury [61-63], ischemic stroke [55, 64, 65], hemorrhagic stroke [66], and tumor [67, 68]. The design of trials to evaluate its effect on edema in brain injured states, such as stroke and traumatic brain injury, is underway.

The formation of cerebral edema is a complex process involving progressive, step-wise, and heterogenous aberrations in molecular processes that regulate brain-fluid physiology. As a result, agents such as bumetanide that selectively target one aspect of the process are likely to be more effective when deployed in combination with agents that target other processes. A complementary and potentially synergistic target for treating cerebral edema exists in the ion channel that functions during ischemia in the complete absence of ATP, the SUR1/TRPM4 channel.

\section{SUR1/TRPM4 Channel}

SUR1 is a regulatory subunit that associates with poreforming subunits to form hetero-octameric $\mathrm{K}_{\mathrm{ATP}}$ channels 
[69]. SUR1 is inhibited directly by sulfonylurea inhibitors, such as glibenclamide (United States' [U.S.] adopted name, glyburide). In addition and also important to the topic of cerebral edema formation, SUR1 also regulates the activity of a nonselective cation channel, the SUR1/TRPM4 channel [70]. This channel conducts monovalent cations, requires nanomolar concentrations of intracellular calcium for opening, and is activated by the depletion of intracellular ATP [71]. The opening of SUR1/TRPM4 channels causes complete depolarization and cell blebbing, characteristic of cytotoxic (cellular) edema. Depolarization and blebbing induced by depletion of ATP are prevented by glibenclamide, consistent with a crucial role for SUR1/ TRPM4 channels in cytotoxic edema [71, 72]. SUR1/ TRPM4 channels represent an important path for sodium flux required for formation of edema, and independent of $\mathrm{Na}^{+}-\mathrm{K}^{+}$-ATPase inactivity seen in ischemia.

Unlike NKCC1, the SUR1/TRPM4 channel is normally absent, but it is transcriptionally upregulated in the setting of ischemic injury. It is also upregulated in the setting of traumatic brain injury [66] and brain tumor [73, 74]. Small mammal models of massive cerebral ischemic injury have been used to demonstrate that the expression of SUR1/ TRPM4 channels is upregulated after ischemia, and targeting SUR1 may provide a new therapeutic approach. SUR1/ TRPM4 channels are crucially involved in the development of cerebral edema and directed inhibition by glibenclamide results in major improvements in stroke outcome. Inhibition of this channel in a mammalian model of stroke using lowdose glibenclamide reduced the formation of edema after ischemia by more than $50 \%$ [75].

The potential of this therapy to be clinically effective is currently being investigated in a clinical trial (Clinicaltrials. gov identifier No. NCT01268683). Inhibition of this channel to prevent cerebral edema has been issued multiple international patents (including U.S. Patent No. 7285574 B2).

Temporally, the SUR1/TRPM4 channel becomes relevant "later" after ischemic injury, when ATP becomes completely depleted and SUR1/TRPM4 channels open, triggering the ATP-independent passive transport of water and solute. The combination regimen of bumetanide plus glibenclamide might be a particularly attractive therapeutic option because it would target both the ATP-dependent and ATP-independent stages of edema development.

\section{Vasopressin Receptor Antagonist}

Hyponatremia is a common electrolyte disorder in the setting of aneurysmal subarachnoid hemorrhage (aSAH) [76]. This is usually attributed to the syndrome of inappropriate antidiuretic hormone (SIADH) secretion [77, 78]. SIADH results in impaired systemic water excretion. Any central nervous system disorder, such as aSAH, can enhance antidiuretic hormone release. The retention of water and development of hyponatremia can have profound effects on the clinical course of patients with aSAH and other neurological disorders. Hyponatremia has been implicated in the development of cerebral edema and subsequent increased intracranial pressure [79, 80]. In the intensive care setting, control of serum sodium levels and volume status are necessary to optimize outcomes and prevent cerebral edema [81, 82].

The first line treatments of hyponatremia associated with SIADH consist of enteral salt repletion, moderate fluid restriction, administration of hypertonic saline, and the use of mineralocorticoids and glucocorticoids [83]. When treating ruptured cerebral aneurysms, measures must also take into consideration the concurrent efforts at hemodilution, relative hypertension, and volume expansion that are often used to prevent or treat cerebral vasospasm [83, 84]. Each of these therapies has its inherent limitations and drawbacks. Fluid restriction is typically insufficient to rapidly normalize serum sodium in critically ill, symptomatic patients. Fluid restriction is also relatively contraindicated in aSAH, as it promotes hypovolemia and can increase the risk of cerebral ischemia [85]. Administration of hypertonic saline does not address the fundamental water imbalance that underlies euvolemic hyponatremia associated with SIADH. Mineralocorticoids, such as fludrocortisone acetate, enhance sodium retention, but have limited efficacy in correcting hyponatremia, and may precipitate volume overload through concurrent water retention [86, 87]. No current therapy promotes renal-free water excretion and opposes the underlying pathophysiology of dilutional hyponatremia observed in SIADH.

Conivaptan, a vasopressin receptor antagonist, can be used in the treatment of aSAH-related euvolemic hyponatermia secondary to SIADH. Conivaptan is a V1A- and V2 (vasopressin)-receptor antagonist [88]. In SIADH, vasopressin binding to the $\mathrm{V} 2$ receptors in the renal collecting ducts promotes free water reabsorption, and by antagonizing these receptors the conivaptan promotes water excretion while sparing electrolytes including sodium. This process, known as aquaresis, results in an increase in serum sodium by reversing the underlying pathophysiology of SIADH $[89,90]$. Multiple studies have been performed to determine the efficacy of conivaptan in patients with euvolemic or hypervolemic hyponatremia. In several double-blind, placebo-controlled clinical trials, conivaptan has been effective in improving serum sodium concentrations [91]. Serum sodium is improved by $6.3 \mathrm{mmol} / \mathrm{L}$ with a $40 \mathrm{mg}$ daily dose, and by $9.0 \mathrm{mmol} / \mathrm{L}$ with an $80 \mathrm{mg}$ daily dose [92-94]. Importantly, despite the properties of conivaptan as a V1a-receptor antagonist, it had no effect on systolic blood pressure or pulse rate. Conivaptan has been found to 
be effective in a heterogenous population of neurointensive care patients $[95,96]$.

Conivaptan is a Food and Drug Administration-approved drug for the treatment of euvolemic hyponatremic patients in a hospitalized setting. By promoting aquaresis, conivaptan directly inhibits the mechanism of pathophysiology in aSAH-related SIADH. Potential benefits of effectively treating this condition are related to a decrease in cerebral edema. Although this has been shown in a rat model of subarachnoid hemorrhage, the effects in humans are yet to be determined [97]. Early reports of vasopressin-receptor antagonism in brain injured patients give preliminary indication that treatment confers an acute osmotic benefit, reducing brain water and thereby intracranial pressure $[98,99]$. Euvolemic normalization of serum sodium with vasopressin antagonism has the potential to minimize cerebral edema for a wide range of neurological diseases and is the subject a current clinical trial proposal.

\section{Conclusion}

Cerebral edema leads to significant morbidity and mortality in the neurointensive care setting. Improved local and systemic control of water homeostasis may be achieved via osmotherapy, inhibition of specific ion transporters, and vasopressin antagonism alone or in combination.

Acknowledgments This work was supported in part by grants from the Department of Veterans Affairs (Baltimore, MD to J.M.S.); the National Heart, Lung and Blood Institute (HL082517 to J.M.S.), and the National Institute of Neurological Disorders and Stroke (NS061808, NS060801 to J.M.S.).

Required Author Forms Disclosure forms provided by the authors are available with the online version of this article. J.M.S. is the holder of several patents related to cerebral edema and ion channels discussed in this article, including "Novel Non-Selective Cation Channel in Neuronal Cells and Methods for Treating Brain Swelling" (U.S. Patent No. 2006/0276411 A1), "Therapeutic Agents Targeting the NCCaATP Channel and Methods of Use Thereof" (U.S > Patent No. 2009/ 0130083 A1), and "Targeting NCCA-ATP Channel for Organ Protection following Ischemic Episode" (U.S. Patent No. 2010/ 0143347 A1).

\section{References}

1. Glaser N, Barnett P, McCaslin I, et al. Risk factors for cerebral edema in children with diabetic ketoacidosis. The Pediatric Emergency Medicine Collaborative Research Committee of the American Academy of Pediatrics. N Engl J Med 2001;344:264-269.

2. Matsuzaki M, Takahashi R, Nakayama T, et al. Disruption of endothelial tight junctions in a patient with mitochondrial encephalomyopathy, lactic acidosis and stroke-like episodes (MELAS). Neuropediatrics 2010;41:72-74.
3. Kahle KT, Walcott BP, Nahed BV, et al. Cerebral edema and a transtentorial brain herniation syndrome associated with pandemic swine influenza A (H1N1) virus infection. J Clin Neurosci 2011;18:1245-1248.

4. Gerstner ER, Duda DG, di Tomaso E, et al. VEGF inhibitors in the treatment of cerebral edema in patients with brain cancer. Nat Rev Clin Oncol 2009;6:229-236.

5. Hofmeijer J, Algra A, Kappelle LJ, van der Worp HB. Predictors of life-threatening brain edema in middle cerebral artery infarction. Cerebrovasc Dis 2008;25:176-184.

6. Hofmeijer J, Kappelle LJ, Algra A, Amelink GJ, van Gijn J, van der Worp HB. Surgical decompression for space-occupying cerebral infarction (the Hemicraniectomy After Middle Cerebral Artery infarction with Life-threatening Edema Trial [HAMLET]): a multicentre, open, randomised trial. Lancet Neurol 2009;8:326333.

7. Simard JM, Sahuquillo J, Sheth KN, Kahle KT, Walcott BP. Managing malignant cerebral infarction. Curr Treat Options Neurol 2011;13:217-229.

8. Wilde EA, McCauley SR, Hunter JV, et al. Diffusion tensor imaging of acute mild traumatic brain injury in adolescents. Neurology 2008;70:948-955.

9. Donkin JJ, Vink R. Mechanisms of cerebral edema in traumatic brain injury: therapeutic developments. Curr Opin Neurol 2010;23:293-299.

10. Simard JM, Kent TA, Chen M, Tarasov KV, Gerzanich V. Brain oedema in focal ischaemia: molecular pathophysiology and theoretical implications. Lancet Neurol 2007;6:258-268.

11. Unterberg AW, Stover J, Kress B, Kiening KL. Edema and brain trauma. Neuroscience 2004;129:1021-1029.

12. King LS, Agre P. Pathophysiology of the aquaporin water channels. Annu Rev Physiol 1996;58:619-648.

13. Manley GT, Fujimura M, Ma T, et al. Aquaporin-4 deletion in mice reduces brain edema after acute water intoxication and ischemic stroke. Nat. Med 2000;6:159-163.

14. Badaut J, Lasbennes F, Magistretti PJ, Regli L. Aquaporins in brain: distribution, physiology, and pathophysiology. J Cereb Blood Flow Metab 2002;22:367-378.

15. Amiry-Moghaddam M, Ottersen OP. The molecular basis of water transport in the brain. Nat Rev Neurosci 2003;4:991-1001.

16. Ribeiro MDC, Hirt L, Bogousslavsky J, Regli L, Badaut J. Time course of aquaporin expression after transient focal cerebral ischemia in mice. J Neurosci Res 2006;83:1231-1240.

17. Banasiak KJ, Burenkova O, Haddad GG. Activation of voltagesensitive sodium channels during oxygen deprivation leads to apoptotic neuronal death. Neuroscience 2004;126:31-44.

18. Beck J, Lenart B, Kintner DB, Sun D. Na-K-Cl Cotransporter Contributes to Glutamate-Mediated Excitotoxicity. J Neurosci 2003;23:5061-5068.

19. Breder J, Sabelhaus CF, Opitz T, Reymann KG, Schröder UH. Inhibition of different pathways influencing $\mathrm{Na}+$ homeostasis protects organotypic hippocampal slice cultures from hypoxic/ hypoglycemic injury. Neuropharmacology 2000;39:1779-1787.

20. Hacke W, Schwab S, Horn M, Spranger M, De Georgia M, von Kummer R. "Malignant" middle cerebral artery territory infarction: clinical course and prognostic signs. Arch Neurol 1996;53:309315.

21. Cruz J, Minoja G, Okuchi K, Facco E. Successful use of the new high-dose mannitol treatment in patients with Glasgow Coma Scale scores of 3 and bilateral abnormal pupillary widening: a randomized trial. J Neurosurg 2004;100:376-383.

22. Chesnut RM, Gautille T, Blunt BA, Klauber MR, Marshall LF. Neurogenic hypotension in patients with severe head injuries. J Trauma 1998;44:958-964.

23. Kaufmann AM, Cardoso ER. Aggravation of vasogenic cerebral edema by multiple-dose mannitol. J Neurosurg 1992;77:584-589. 
24. Ware ML, Nemani VM, Meeker M, Lee C, Morabito DJ, Manley GT. Effects of $23.4 \%$ sodium chloride solution in reducing intracranial pressure in patients with traumatic brain injury: a preliminary study. Neurosurgery 2005;57:727-736.

25. Kerwin AJ, Schinco MA, Tepas JJ 3rd, Renfro WH, Vitarbo EA, Muehlberger $\mathrm{M}$. The use of $23.4 \%$ hypertonic saline for the management of elevated intracranial pressure in patients with severe traumatic brain injury: a pilot study. J Trauma 2009;67:277282.

26. Weed LH, McKibben PS. Experimental alteration of brain bulk. Am J Physiol 1919;48:531-558.

27. Qureshi AI, Suarez JI. Use of hypertonic saline solutions in treatment of cerebral edema and intracranial hypertension. Crit Care Med 2000;28:3301-3313.

28. Koenig MA, Bryan M, Lewin JL, Mirski MA, Geocadin RG, Stevens RD. Reversal of transtentorial herniation with hypertonic saline. Neurology 2008;70:1023-1029.

29. Zeynalov E, Chen C, Froehner SC, et al. The perivascular pool of aquaporin-4 mediates the effect of osmotherapy in postischemic cerebral edema. Crit Care Med 2008;36:2634-2640.

30. Gundersen Y, Ruud TE, Krohn CD, Sveen O, Lyngstadaas SP, Aasen AO. Impact of hypertonic saline on the release of selected cytokines after stimulation with LPS or peptidoglycan in ex vivo whole blood from healthy humans. Shock 2010;34:450-454.

31. Jin QH, Ueda Y, Ishizuka Y, Kunitake T, Kannan H. Cardiovascular changes induced by central hypertonic saline are accompanied by glutamate release in awake rats. Am J Physiol Regul Integr Comp Physiol 2001;281:R1224-R1231.

32. Chodobski A. Possible new mechanism underlying hypertonic saline therapy for cerebral edema. J Appl Physiol 2006;100:14371438.

33. Qureshi AI, Wilson DA, Traystman RJ. Treatment of transtentorial herniation unresponsive to hyperventilation using hypertonic saline in dogs: effect on cerebral blood flow and metabolism. J Neurosurg Anesthesiol 2002;14:22-30.

34. Qureshi AI, Suri MFK, Ringer AJ, Guterman LR, Hopkins LN. Regional intraparenchymal pressure differences in experimental intracerebral hemorrhage: effect of hypertonic saline. Crit Care Med 2002;30:435-441

35. Toung TJ, Nyquist P, Mirski MA. Effect of hypertonic saline concentration on cerebral and visceral organ water in an uninjured rodent model. Crit Care Med 2008;36:256-261.

36. Qureshi AI, Wilson DA, Traystman RJ. Treatment of elevated intracranial pressure in experimental intracerebral hemorrhage: comparison between mannitol and hypertonic saline. Neurosurgery 1999;44:1055-1064.

37. Suarez JI, Qureshi AI, Bhardwaj A, et al. Treatment of refractory intracranial hypertension with $23.4 \%$ saline. Crit Care Med 1998;26:1118-1122.

38. Rockswold GL, Solid CA, Paredes-Andrade E, Rockswold SB, Jancik JT, Quickel RR. Hypertonic saline and its effect on intracranial pressure, cerebral perfusion pressure, and brain tissue oxygen. Neurosurgery 2009;65:1035-1042.

39. Delashaw JB, Broaddus WC, Kassell NF, Haley EC, Pendleton GA, Vollmer DG, et al. Treatment of right hemispheric cerebral infarction by hemicraniectomy. Stroke 1990;21:874-881.

40. Schwab S, Steiner T, Aschoff A, et al. Early hemicraniectomy in patients with complete middle cerebral artery infarction. Stroke 1998;29:1888-1893.

41. Fisher CM, Ojemann RG. Bilateral decompressive craniectomy for worsening coma in acute subarachnoid hemorrhage. Observations in support of the procedure. Surg Neurol 1994;41:65-74.

42. Carter BS, Ogilvy CS, Candia GJ, Rosas HD, Buonanno F. Oneyear outcome after decompressive surgery for massive nondominant hemispheric infarction. Neurosurgery 1997;40:1168-1176.
43. Uhl E, Kreth FW, Elias B, et al. Outcome and prognostic factors of hemicraniectomy for space occupying cerebral infarction. J Neurol Neurosurg Psychiatr 2004;75:270-274.

44. Jüttler E, Schwab S, Schmiedek P, et al. Decompressive Surgery for the Treatment of Malignant Infarction of the Middle Cerebral Artery (DESTINY): a randomized, controlled trial. Stroke 2007;38:2518-2525.

45. Vahedi K, Vicaut E, Mateo J, et al. Sequential-design, multicenter, randomized, controlled trial of early decompressive craniectomy in malignant middle cerebral artery infarction (DECIMAL Trial). Stroke 2007;38:2506-2517.

46. Frank J. Hemicraniectomy and durotomy upon deterioration from infarction related swelling trial (HeADDFIRST): first public presentation of the primary study findings. Neurology 2003;(60 suppl 1):A426.

47. Walberer M, Ritschel N, Nedelmann M, et al. Aggravation of infarct formation by brain swelling in a large territorial stroke: a target for neuroprotection? J Neurosurg 2008;109:287-293.

48. Cooper DJ, Rosenfeld JV, Murray L, et al. Decompressive craniectomy in diffuse traumatic brain injury. $\mathrm{N}$ Engl J Med 2011;364:1493-1502.

49. Smith DS, Rehncrona S, Siesjö BK. Barbiturates as protective agents in brain ischemia and as free radical scavengers in vitro. Acta Physiol Scand Suppl 1980;492:129-134.

50. Qizilbash N, Lewington SL, Lopez-Arrieta JM. Corticosteroids for acute ischaemic stroke. Cochrane Database Syst Rev 2002;(2): CD000064

51. Betz AL, Iannotti F, Hoff JT. Brain edema: a classification based on blood-brain barrier integrity. Cerebrovasc Brain Metab Rev 1989;1:133-154

52. Young W, Rappaport Z, Chalif D, Flamm E. Regional brain sodium, potassium, and water changes in the rat middle cerebral artery occlusion model of ischemia. Stroke 1987;18:751-759.

53. Kahle KT, Staley KJ, Nahed BV, et al. Roles of the cationchloride cotransporters in neurological disease. Nat Clin Pract Neurol 2008;4:490-503.

54. Yan Y, Dempsey RJ, Sun D. $\mathrm{Na}+-\mathrm{K}+-\mathrm{Cl}-$ cotransporter in rat focal cerebral ischemia. J Cereb Blood Flow Metab 2001;21:711721.

55. Yan Y, Dempsey RJ, Flemmer A, Forbush B, Sun D. Inhibition of $\mathrm{Na}(+)-\mathrm{K}(+)-\mathrm{Cl}(-)$ cotransporter during focal cerebral ischemia decreases edema and neuronal damage. Brain Res 2003;961:2231.

56. Su G, Kintner DB, Flagella M, Shull GE, Sun D. Astrocytes from $\mathrm{Na}+-\mathrm{K}+-\mathrm{Cl}-$ cotransporter-null mice exhibit absence of swelling and decrease in EAA release. American J Physiol Cell Physiol 2002;282:C1147-C1160

57. Su G, Kintner DB, Sun D. Contribution of $\mathrm{Na}+-\mathrm{K}+-\mathrm{Cl}-$ cotransporter to high- $[\mathrm{K}+] \mathrm{o}-$ induced swelling and EAA release in astrocytes. Am J Physiol Cell Physiol 2002;282: C1136-C1146.

58. Chen H, Sun D. The role of Na-K-Cl co-transporter in cerebral ischemia. Neurol Res 2005;27:280-286.

59. Staley KJ. Wrong-way chloride transport: is it a treatable cause of some intractable seizures? Epilepsy Curr 2006;6:124-127.

60. Maa EH, Kahle KT, Walcott BP, Spitz MC, Staley KJ. Diuretics and epilepsy: will the past and present meet? Epilepsia 2011;52 (9):1559-1569.

61. Lu K, Cheng N, Wu C, Yang Y. NKCC1-mediated traumatic brain injury-induced brain edema and neuron death via Raf/MEK/ MAPK cascade. Crit Care Med 2008;36:917-922.

62. Lu K, Wu C, Yen H, Peng JF, Wang C, Yang Y. Bumetanide administration attenuated traumatic brain injury through IL-1 overexpression. Neurol Res 2007;29:404-409.

63. $\mathrm{Lu} \mathrm{K}, \mathrm{Wu} \mathrm{C}$, Cheng $\mathrm{N}$, et al. Inhibition of the $\mathrm{Na}+-\mathrm{K}+-2 \mathrm{Cl}-$ cotransporter in choroid plexus attenuates traumatic brain injury- 
induced brain edema and neuronal damage. Eur $\mathrm{J}$ Pharmacol 2006;548:99-105.

64. Chen H, Luo J, Kintner DB, Shull GE, Sun D. Na(+)-dependent chloride transporter (NKCC1)-null mice exhibit less gray and white matter damage after focal cerebral ischemia. J Cereb Blood Flow Metab 2005;25:54-66.

65. Simard JM, Chen M, Tarasov KV, et al. Newly expressed SUR1regulated $\mathrm{NC}(\mathrm{Ca}-\mathrm{ATP})$ channel mediates cerebral edema after ischemic stroke. Nat Med 2006;12:433-440.

66. Simard JM, Kahle KT, Gerzanich V. Molecular mechanisms of microvascular failure in central nervous system injury synergistic roles of NKCC1 and SUR1/TRPM4. J Neurosurg 2010;113:622-629.

67. Conti L, Palma E, Roseti C, et al. Anomalous levels of Cltransporters cause a decrease of GABAergic inhibition in human peritumoral epileptic cortex. Epilepsia 2011;52:1635-1644.

68. Haas BR, Sontheimer H. Inhibition of the sodium-potassiumchloride cotransporter isoform-1 reduces glioma invasion. Cancer Res 2010;70:5597-5606.

69. Seino S. ATP-sensitive potassium channels: a model of heteromultimeric potassium channel/receptor assemblies. Annu Rev Physiol 1999;61:337-362.

70. Chang Y, Chen T, Chen C, Crain BJ, Toung TJK, Bhardwaj A. Plasma arginine-vasopressin following experimental stroke: effect of osmotherapy. J Appl Physiol 2006;100:1445-1451.

71. Chen M, Simard JM. Cell swelling and a nonselective cation channel regulated by internal $\mathrm{Ca} 2+$ and ATP in native reactive astrocytes from adult rat brain. J Neurosci 2001;21:6512-6521.

72. Chen M, Dong Y, Simard JM. Functional coupling between sulfonylurea receptor type 1 and a nonselective cation channel in reactive astrocytes from adult rat brain. J Neurosci 2003;23:85688577.

73. Ningaraj NS, Rao MK, Black KL. Adenosine 5'-triphosphatesensitive potassium channel-mediated blood-brain tumor barrier permeability increase in a rat brain tumor model. Cancer Res 2003;63:8899-8911.

74. Zhang H, Gu YT, Xue YX. Bradykinin-induced blood-brain tumor barrier permeability increase is mediated by adenosine 5'triphosphate-sensitive potassium channel. Brain Res 2007;1144:3341.

75. Simard JM, Tsymbalyuk N, Tsymbalyuk O, Ivanova S, Yurovsky V, Gerzanich V. Glibenclamide is superior to decompressive craniectomy in a rat model of malignant stroke. Stroke 2010;41:531-537.

76. Wijdicks EF, Ropper AH, Hunnicutt EJ, Richardson GS, Nathanson JA. Atrial natriuretic factor and salt wasting after aneurysmal subarachnoid hemorrhage. Stroke 1991;22:15191524.

77. Sherlock M, O'Sullivan E, Agha A, et al. The incidence and pathophysiology of hyponatraemia after subarachnoid haemorrhage. Clin Endocrinol (Oxf) 2006;64:250-254.

78. Wartenberg KE, Schmidt JM, Claassen J, et al. Impact of medical complications on outcome after subarachnoid hemorrhage. Crit Care Med 2006;34:617-624.

79. Hasan D, Wijdicks EF, Vermeulen M. Hyponatremia is associated with cerebral ischemia in patients with aneurysmal subarachnoid hemorrhage. Ann Neurol 1990;27:106-108.

80. Soupart A, Decaux G. Therapeutic recommendations for management of severe hyponatremia: current concepts on pathogenesis and prevention of neurologic complications. Clin Nephrol 1996;46:149-169.
81. Upadhyay UM, Gormley WB. Etiology and management of hyponatremia in neurosurgical patients. J Intensive Care Med 2011;Feb 23 [online]:PMID 21345881.

82. Diringer MN, Zazulia AR. Hyponatremia in neurologic patients: consequences and approaches to treatment. Neurologist 2006;12:117-126.

83. Rahman M, Friedman WA. Hyponatremia in neurosurgical patients: clinical guidelines development. Neurosurgery 2009;65:925-936.

84. Origitano TC, Wascher TM, Reichman OH, Anderson DE. Sustained increased cerebral blood flow with prophylactic hypertensive hypervolemic hemodilution ("triple- $\mathrm{H}$ " therapy) after subarachnoid hemorrhage. Neurosurgery 1990;27:729-740.

85. Wijdicks EF, Vermeulen M, Hijdra A, van Gijn J. Hyponatremia and cerebral infarction in patients with ruptured intracranial aneurysms: is fluid restriction harmful? Ann Neurol 1985;17:137-140.

86. Woo MH, Kale-Pradhan PB. Fludrocortisone in the treatment of subarachnoid hemorrhage-induced hyponatremia. Ann Pharmacother 1997;31:637-639.

87. Wijdicks EF, Vermeulen M, van Brummelen P, van Gijn J. The effect of fludrocortisone acetate on plasma volume and natriuresis in patients with aneurysmal subarachnoid hemorrhage. Clin Neurol Neurosurg 1988;90:209-214.

88. Cawley MJ. Hyponatremia: current treatment strategies and the role of vasopressin antagonists. Ann Pharmacother 2007;41:840 850.

89. Hays RM. Vasopressin antagonists - progress and promise. $\mathrm{N}$ Engl J Med 2006;355:2146-2148.

90. Palm C, Pistrosch F, Herbrig K, Gross P. Vasopressin antagonists as aquaretic agents for the treatment of hyponatremia. Am J Med 2006;119(7 suppl 1):S87-S92.

91. Decaux G, Soupart A, Vassart G. Non-peptide arginine-vasopressin antagonists: the vaptans. Lancet 2008;371:1624-1632.

92. Zeltser D, Rosansky S, van Rensburg H, Verbalis JG, Smith N. Assessment of the efficacy and safety of intravenous conivaptan in euvolemic and hypervolemic hyponatremia. Am J Nephrol 2007;27:447-457.

93. Yeates KE, Morton AR. Vasopressin antagonists: role in the management of hyponatremia. Am J Nephrol 2006;26:348-355.

94. Ghali JK, Koren MJ, Taylor JR, et al. Efficacy and safety of oral conivaptan: a V1A/V2 vasopressin receptor antagonist, assessed in a randomized, placebo-controlled trial in patients with euvolemic or hypervolemic hyponatremia. J Clin Endocrinol Metab 2006;91:2145-2152.

95. Murphy T, Dhar R, Diringer M. Conivaptan bolus dosing for the correction of hyponatremia in the neurointensive care unit. Neurocrit Care 2009;11:14-19.

96. Wright WL, Asbury WH, Gilmore JL, Samuels OB. Conivaptan for hyponatremia in the neurocritical care unit. Neurocrit Care 2009;11:6-13.

97. László FA, Varga C, Dóczi T. Cerebral oedema after subarachnoid haemorrhage. Pathogenetic significance of vasopressin. Acta Neurochir (Wien) 1995;133:122-133.

98. Dhar R, Murphy-Human T. A bolus of conivaptan lowers intracranial pressure in a patient with hyponatremia after traumatic brain injury. Neurocrit Care 2011;14:97-102.

99. Galton C, Deem S, Yanez ND, Souter M, Chesnut R, Dagal A, et al. Open-label randomized trial of the safety and efficacy of a single dose conivaptan to raise serum sodium in patients with traumatic brain injury. Neurocrit Care 2011;14:354-360. 